\title{
Paleointensity determination of Late Cretaceous basalts in northwest South Korea: implications for low and stable paleofield strength in the Late Cretaceous
}

\author{
Bongsu Chang ${ }^{1}$, Wonnyon $\mathrm{Kim}^{2}$, Seong-Jae Doh ${ }^{1}$, and Yongjae $\mathrm{Yu}^{3}$ \\ ${ }^{1}$ Department of Earth and Environmental Sciences, Korea University, Seoul, 136-713, Republic of Korea \\ ${ }^{2}$ Deep-sea and Seabed Resources Research Division, Korea Institute of Ocean Science and Technology, Ansan, 426-744, Republic of Korea \\ ${ }^{3}$ Department of Geology and Earth Environmental Sciences, Chungnam National University, Daejeon, 305-764, Republic of Korea
}

(Received June 19, 2013; Revised September 26, 2013; Accepted September 27, 2013; Online published December 6, 2013)

\begin{abstract}
To clarify geomagnetic field behavior in the Late Cretaceous, paleointensity and rock-magnetic studies were carried out on basalts with K-Ar ages of $78.6 \pm 2.5$ and $73.1 \pm 1.6 \mathrm{Ma}$ in northwest South Korea. A total of 314 samples (262 from six lava flows and 52 from massive basalts) were subjected to Thellier-type IZZI paleointensity experiments. Through the application of seven paleointensity selection criteria that mainly verify the thermal alteration of magnetic minerals and the stability of remanence direction, fifteen paleointensity data were obtained from five of the lava flows. Based on rock-magnetic experiments and microscopic observations, it is revealed that the measured paleointensity is carried by single-domain (titano)magnetite. The site-mean paleointensities ranged 13.1-21.3 $\mu \mathrm{T}$, which corresponds to a virtual axial dipole moment of $2.3-3.8 \times 10^{22} \mathrm{Am}^{2}$. The combination of this result with selected data from the IAGA paleointensity database establishes the existence of different dipole moments according to rock type. In particular, the geomagnetic field strength recorded in Late Cretaceous crystalline volcanic rock was relatively low and stable, with a mean dipole moment of $4.0 \pm 1.9 \times 10^{22} \mathrm{Am}^{2}$ regardless of geomagnetic field reversals.
\end{abstract}

Key words: Basalts, IZZI protocol, Korea, Late Cretaceous, paleointensity.

\section{Introduction}

The Earth's magnetic field is generated by electrical currents flowing in the liquid outer core and is sustained permanently by a self-exciting geodynamo (e.g., Glatzmaier et al., 1999). The stability of the field is known to be controlled by the thermal structure in the core-mantle boundary, based on the analysis of the statistical properties of marine magnetic anomaly time scales (McFadden and Merrill, 1984) and a numerical simulation of the geodynamo (Olson et al., 2010). McFadden and Merrill (1984) proposed that long periods of geomagnetic polarity without any reversals are related to vigorous thermal activity at the base of the mantle. In contrast, Olson et al. (2010) suggested that periods of frequent change in geomagnetic polarity may be linked to heat flow increase at the core-mantle boundary. Thus, information about the variation in the strength of the Earth's magnetic field over geologic time periods can provide valuable insights into the evolution of Earth as a planet. In the last few decades, numerous studies have tried to collect more detailed information on the variation in paleofield intensities. Paleointensity data, however, are still insufficient in terms of temporal and spatial resolution to be reliable (see the IAGA absolute paleointensity [PINT] database; Biggin et al., 2010) because of the scarceness of suitable materials

Copyright (C) The Society of Geomagnetism and Earth, Planetary and Space Sciences (SGEPSS); The Seismological Society of Japan; The Volcanological Society of Japan; The Geodetic Society of Japan; The Japanese Society for Planetary Sciences; TERRAPUB.

doi:10.5047/eps.2013.09.013 and magnetomineralogical alterations during experiments.

One of the most dramatic changes in the geomagnetic field since the Mesozoic occurred in the Late Cretaceous. After a long period of normal geomagnetic polarity (the Cretaceous Normal Superchron, CNS, 38 Myr), the reversal rate of the geomagnetic field began to increase from zero to 1.08 reversals per million years until $\sim 60 \mathrm{Ma}$ (McFadden and Merrill, 1997). The directional records of the geomagnetic field are well documented for that time, but the characteristics of paleointensity are not as well known, even though the paleointensity during the Late Cretaceous plays an important role in understanding the Earth's evolution in relation to geomagnetic field reversal and heat flow across the core-mantle boundary. It is notable that the PINT database (Biggin et al., 2010) presents only four paleointensity studies (Juárez et al., 1998; Smirnov and Tarduno, 2003; Tauxe, 2006; Shcherbakova et al., 2007) satisfying modern standards (i.e., the use of the doubleheating method with alteration checks) within the time interval 83-72 Ma. Of these, three studies used submarine basaltic glass (SBG) as an experimental material: Juárez et al. (1998) reported a high dipole moment of $9.0 \pm 0.7$ $\times 10^{22} \mathrm{Am}^{2}$ at $\sim 72 \mathrm{Ma}$; Tauxe (2006) suggested $11.3 \pm$ $0.7 \times 10^{22} \mathrm{Am}^{2}$ at $\sim 72 \mathrm{Ma}$ and $6.8 \pm 5.1 \times 10^{22} \mathrm{Am}^{2}$ at 77.6 Ma; and Smirnov and Tarduno (2003) documented a low dipole moment of $2.1 \pm 0.7 \times 10^{22} \mathrm{Am}^{2}$ at $\sim 76 \mathrm{Ma}$. The only study to have obtained paleointensity data from basalts (Shcherbakova et al., 2007) showed a low dipole moment of $3.3 \pm 0.1 \times 10^{22} \mathrm{Am}^{2}$ at $\sim 77.6 \mathrm{Ma}$. Given 


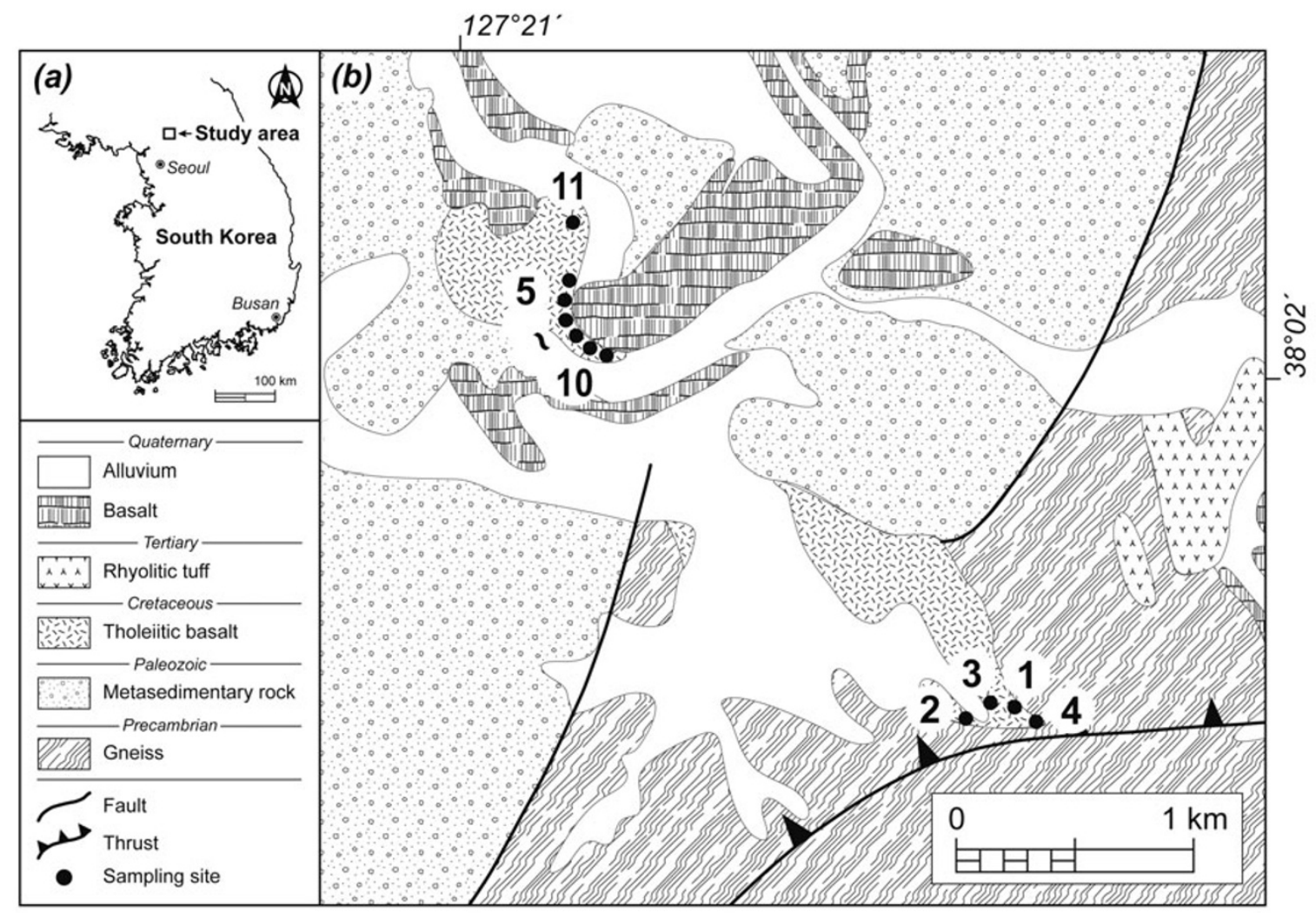

Fig. 1. (a) Map of the Korean Peninsula showing the location of the study area. (b) Geologic map of the study area (modified from Kee et al., 2008). Solid circles represent the locations of sampling sites. Sites 1-4 and 11 are massive basalts and sites 5-10 are lava flows.

that the time interval of 83-72 Ma has been suggested to correspond with a stationary regime for the geodynamo and a low geomagnetic reversal rate (Gallet and Hulot, 1997), high dipole moments are plausible, as suggested by numerical simulation (e.g., Olson and Hagee, 1990). However, such a discrepancy between the dipole moments of various studies could be explained by the materials used for the experiments, given that the magnetic minerals in SBG are sometimes chemically altered during paleointensity experiments (Heller et al., 2002; Smirnov and Tarduno, 2003). Hence, paleointensity data obtained from magnetically stable volcanic rocks are needed to clarify geomagnetic field behavior in the Late Cretaceous.

In this study, paleointensity and rock-magnetic analyses were performed on Late Cretaceous basalts in northwest South Korea to provide more detail on paleointensity during the Late Cretaceous. In addition, paleointensity variation between different rock types is discussed using data from the PINT database.

\section{Samples}

Volcanic activity during the Cretaceous-Paleogene period was prevalent on the Korean Peninsula, leaving behind abundant outcrops of volcanic rocks. Of these, we focused on basalts in the Yeoncheon area of South Korea (Fig. 1), which formed during the Late Cretaceous after the CNS. These basalts have several advantages in determining paleointensity. First of all, the recorded remanence is thought to preserve the primary geomagnetic field according to a previous paleomagnetic study by Lee et al. (2001). Based on rock-magnetic analyses including thermomagnetic analysis and microscopic observation, they reported that the basalts contained primary thermoremanent magnetization (TRM) in magnetite without any mineralogical or chemical alteration. In addition, a possible thermal overprint was rejected because the remanent directions of the basalts did not mimic those of later thermal sources (upper layered Late Cretaceous rhyolitic tuff, which passed a conglomerate test, and Quaternary basalts). Although it has a large error range probably due to locally developed strike-slip faults (Lee $e t$ al., 2001), the estimated paleomagnetic pole in this study is consistent at the $95 \%$ confidence level with reported (Late) Cretaceous paleopoles (Fig. 2). Secondly, the basalts are exposed in the form of both six-layered lava flows and massive bodies of maximum height $\sim 100 \mathrm{~m}$, with $\mathrm{K}$-Ar radiometric ages of $73.1 \pm 1.6 \mathrm{Ma}$ and $78.6 \pm 2.5 \mathrm{Ma}$, respectively (Lee, 1989). The six-layered consecutive lava flows and massive basalts are considered to cover a sufficient time span to average out the influence of paleosecular variation to yield representative paleointensity estimates.

The basalts are characterized by a dark grey color with a dominance of plagioclase and clinopyroxene, and are classified as tholeiitic basalt (Lee et al., 1983). For the paleointensity estimate, a total of 268 cores were collected from eleven sites: one site within each of the six layers of the lava flows (182 cores) and five sites within the massive basalts (86 cores). The sampling locations are shown in Fig. 1(b). The cores were oriented in-situ using an orientation device equipped with both a magnetic compass and a sun compass. In the laboratory, the cylindrical cores were cut into 


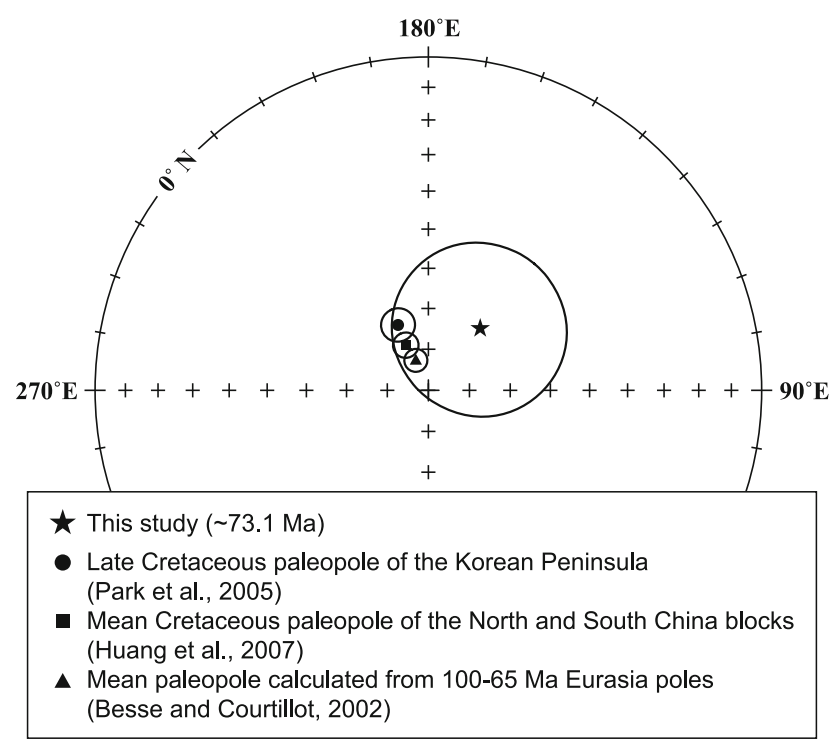

Fig. 2. The paleomagnetic pole of this study calculated using field-off principal components in Thellier experiments (star). Reported (Late) Cretaceous paleopoles are also shown for comparison.

standard-sized samples $(25 \mathrm{~mm}$ in diameter and $22 \mathrm{~mm}$ in length).

\section{Experiments}

Paleointensity experiments were carried out for 314 samples using the in-field/zero-field and zero-field/in-field (IZZI) experimental protocol (Tauxe and Staudigel, 2004; Yu et al., 2004) of the modified Thellier-type doubleheating method (Thellier and Thellier, 1959), with partial thermoremanent magnetization (pTRM) checks. The pTRM checks were performed at every second heating step to detect magnetomineralogical changes produced by heating throughout the paleointensity experiment. The details of the experimental procedure for PTRM checks have been described in several studies (e.g., Coe et al., 1978; Selkin and Tauxe, 2000; Tauxe and Staudigel, 2004). The IZZI protocol consists of two double-heating procedures (infield/zero-field [IZ] and zero-field/in-field [ZI]), and the IZ procedure alternates with the ZI procedure for every other temperature step. Compared to other methods, the IZZI method has an advantage in checking remanence stability (Yu and Tauxe, 2005) by testing an equivalence of blocking and unblocking temperatures without additional heating steps in a zero-field condition (e.g., McClelland and Briden, 1996; Riisager and Riisager, 2001). To impart TRM on the samples during each in-field step, a laboratory field $\left(\mathrm{B}_{\text {lab }}=25 \mu \mathrm{T}\right.$ in this study) was applied along a sample's Z-axis. Thermal treatment was performed using the MMTD-80 thermal demagnetizer from Magnetic Measurements, and the remanence was measured using a Molspin spinner magnetometer. The temperature steps were $200^{\circ} \mathrm{C}, 300^{\circ} \mathrm{C}, 350^{\circ} \mathrm{C}, 400^{\circ} \mathrm{C}, 450^{\circ} \mathrm{C}, 500^{\circ} \mathrm{C}, 520^{\circ} \mathrm{C}$, $540^{\circ} \mathrm{C}, 560^{\circ} \mathrm{C}, 570^{\circ} \mathrm{C}, 585^{\circ} \mathrm{C}$, and $600^{\circ} \mathrm{C}$. In some cases, additional temperature steps of $550^{\circ} \mathrm{C}$ and $555^{\circ} \mathrm{C}$ were applied because the remanence rapidly unblocked within the temperature interval $540-560^{\circ} \mathrm{C}$. At every heating step, the set temperature was reproducible within $<2^{\circ} \mathrm{C}$. The experimental results are presented on an Arai plot (Nagata et al.,
1963), in which the natural remanent magnetization (NRM) remaining after the zero-field step is plotted against the corresponding pTRM gained in the $\mathrm{B}_{\text {lab }}$ for successive heating steps. In an ideal case, the ratio of NRM lost $\left(\mathrm{M}_{\text {anc }}\right)$ to pTRM gained $\left(\mathrm{M}_{\mathrm{lab}}\right)$ remains constant throughout the entire temperature interval. For each sample, the ratio of $\mathrm{M}_{\mathrm{anc}} / \mathrm{M}_{\mathrm{lab}}$ is obtained from the slope of the best-fit line for the NRM-pTRM data points within a selected temperature interval. The Earth's ancient magnetic field $\left(\mathrm{B}_{\mathrm{anc}}\right)$ is then calculated as $B_{a n c}=M_{a n c} / M_{\text {lab }} \times B_{\text {lab }}$. The anisotropy of an anhysteretic remanent magnetization (AARM) tensor was also obtained for eight selected samples following the experimental procedure suggested by Selkin et al. (2000). To check the effects of remanence anisotropy on $B_{a n c}$, vector components for the measured remanences during the paleointensity experiments were corrected using the AARM tensor.

To identify magnetic carriers, thermal demagnetization of 3-axis isothermal remanent magnetization (IRM) (Lowrie, 1990) was conducted for 33 representative samples (three for each sampling site). Magnetizing fields of $2.5 \mathrm{~T}, 0.6 \mathrm{~T}$, and $0.12 \mathrm{~T}$ were applied to the Z-, Y-, and Xaxis respectively of a sample using an ASC Scientific IM10-30 impulse magnetizer. The sample was then thermally demagnetized up to $700^{\circ} \mathrm{C}$ over 19 steps using an ASC Scientific TD-48 thermal demagnetizer. In addition, the temperature dependence of a magnetic susceptibility $(k-T)$ curve was measured using a Bartington MS2 susceptibilitytemperature system with a MS2WF furnace. The heating and cooling rate of the furnace was $\sim 3.5^{\circ} \mathrm{C} / \mathrm{min}$. The Curie temperature $\left(T_{\mathrm{c}}\right)$ was determined from the point with the maximum gradient on the heating curve. In order to diagnose the domain state of magnetic minerals, hysteresis parameters at room temperature, including saturation remanent magnetization $\left(M_{\mathrm{rs}}\right)$, saturation magnetization $\left(M_{\mathrm{s}}\right)$, and coercive force $\left(H_{\mathrm{c}}\right)$, were measured using a Molspin vibrating sample magnetometer with a maximum magnetic field of $1 \mathrm{~T}$. The coercivity of remanence $\left(H_{\mathrm{cr}}\right)$ was deter- 
Table 1. Summary of the seven criteria for selecting paleointensity.

\begin{tabular}{|c|c|c|c|}
\hline Criterion & Implication & Threshold & Ref. \\
\hline Number of points $\left(\mathrm{N}_{\mathrm{p}}\right)$ & To obtain reliable paleointensity statistics & $\geq 7$ & - \\
\hline Maximum angular deviation (MAD) & To ensure stability of remanence direction & $\leq 5^{\circ}$ & {$[1]$} \\
\hline Deviation angle (DANG) & To guarantee remanence direction toward the origin & $\leq 5^{\circ}$ & {$[2]$} \\
\hline Scatter parameter $(\sigma /|b|)$ & To assure straightness of the selected data points & $\leq 0.1$ & {$[3]$} \\
\hline Fraction of the NRM $(f)$ & To avoid under- and over-estimated paleointensity & $\geq 0.5$ & {$[3]$} \\
\hline pTRM check $\left(\mathrm{CK}_{\text {error }}\right)$ & To ensure little influence of thermal alteration & $\leq 5 \%$ & {$[4]$} \\
\hline Quality factor $(q)$ & To ensure high-quality paleointensity data & $\geq 10$ & {$[3]$} \\
\hline
\end{tabular}

$\mathrm{N}_{\mathrm{p}}$ : the number of points used for paleointensity determination on the Arai plot; MAD: maximum angular deviation (Kirschvink, 1980); DANG: deviation angle (Tauxe and Staudigel, 2004); $\sigma /|b|$ : the relative uncertainty of the slope determination, where $b$ is a least squares slope on the Arai plot and $\sigma$ is its standard error (Coe et al., 1978); $f$ : fraction of the NRM (Coe et al., 1978); CKerror: the difference between repeat pTRM steps normalized by the intersection of the best-fit line with the pTRM axis on the Arai plot (Leonhardt et al., 2000); $q$ : quality factor defined by $|b| \cdot f \cdot g / \sigma$, where $g$ is the gap factor (Coe et al., 1978). [1] Kirschvink (1980), [2] Tauxe and Staudigel (2004), [3] Coe et al. (1978), [4] Leonhardt et al. (2000).

mined from the pattern of the hysteresis loop, where the reverse field reduces the remanence to zero, using PmagPy software (Jackson et al., 1990; Tauxe, 2010). After the magnetic measurements, electron microscopic observation was carried out for the selected samples using a Hitachi S-4800 FESEM integrated with energy dispersive X-ray spectroscopy to identify the morphological features and the chemical composition of the magnetic minerals in the samples.

\section{Paleointensity}

\subsection{Paleointensity selection criteria}

There are a number of parameters to describe the behavior of experimental paleointensity data (e.g., Coe et al., 1978; Kirschvink, 1980; Leonhardt et al., 2000; Selkin and Tauxe, 2000; Tauxe and Staudigel, 2004; Paterson, 2011; $\mathrm{Yu}, 2012$ ). Of these, seven paleointensity selection criteria are used in this study (Table 1) to produce reliable paleointensity estimates. The seven criteria focus on stable and uni-vectorial paleomagnetic vectors, the linear relationship between NRM lost and pTRM gained, and the thermal alteration of magnetic minerals during repeated heating steps. The first selection criterion is the use of at least seven consecutive data points $\left(\mathrm{N}_{\mathrm{p}} \geq 7\right)$ for a selected temperature interval on a vector diagram or an Arai plot are used in calculating paleointensity statistical parameters. For the second criterion, the maximum angular deviation (MAD; Kirschvink, 1980) of the data points on a vector diagram determined from a free-floating fit without the origin included is limited to $\leq 5^{\circ}$ to ensure the stability of remanence direction. Third, the deviation angle (DANG; Tauxe and Staudigel, 2004), which is the angle between a best-fit line using the free-floating fit on a vector diagram for selected data points and a line connecting the center of mass of these data points with the origin, is also limited to $\leq 5^{\circ}$ to guarantee a remanence direction trending toward the origin. On an Arai plot, paleointensity estimates depend markedly on the linear relationship between $\mathrm{M}_{\mathrm{anc}}$ and $\mathrm{M}_{\mathrm{lab}}$. Hence, for the fourth criterion, the scatter parameter $(\sigma /|b|$; Coe et al., $1978)$, represented by the standard error of the slope $(\sigma)$ divided by the slope $(|b|)$, is restricted to $\leq 0.1$. In addition, as the calculated slope should represent the overall remanence range with high linearity, the fraction of the NRM
( $f$; Coe et al., 1978) is set to $\geq 0.5$ as the fifth criterion. The difference between the pTRM check and the pTRM at the same temperature is normalized by the maximum TRM that the sample can acquire $\left(\mathrm{CK}_{\text {error }}\right.$; Leonhardt et al., 2000) to identify the thermal alteration of magnetic minerals during repeated heating steps. The maximum acceptable limit for the $\mathrm{CK}_{\text {error }}$ is fixed to $5 \%$ and used as the sixth criterion. The overall quality of the individual paleointensity determination can be evaluated using a quality factor $(q$; Coe et al., 1978) based on several statistical parameters such as $\sigma /|b|, f$, and the gap factor ( $g$; Coe et al., 1978). In general, high-quality paleointensity data have a relatively low $\sigma /|b|$, a high $f$, and a high $g$. Thus, the lower threshold of $q$ is set to 10 as the final criterion to ensure high-quality paleointensity data. The thresholds for the above seven criteria are in line with other similar paleointensity studies dealing with Cretaceous volcanic rocks.

\subsection{Paleointensity determinations}

Representative results for the paleointensity experiments are shown in Figs. 3 and 4. Figure 3 presents examples of the Arai plot for results that passed the seven paleointensity selection criteria, including the pTRM check. The data points, representing the IZ (closed circle) and ZI (open circle) procedures, form a single straight line on the Arai plot, and the pTRM checks (triangles) overlap with, or remain close to, the initial measurements (a positive pTRM check). Notably, $>50 \%$ of the NRM components decay within a narrow temperature range of $500-585^{\circ} \mathrm{C}$, and the typical maximum unblocking temperatures are near 585$600^{\circ} \mathrm{C}$ (Fig. 3). In addition, the remanence direction of a single component running toward the origin can be identified on the vector diagrams (insets in Fig. 3) obtained from each demagnetization step (i.e., the zero-field step during IZ and ZI procedures) throughout the paleointensity experiments. In the case of the sample of YC08-19 (Fig. 3(b)), for instance, the calculated values of $\mathrm{N}_{\mathrm{p}}$, MAD, DANG, $\sigma /|b|$, $f, \mathrm{CK}_{\mathrm{error}}$, and $q$ for the temperature interval of $450-585^{\circ} \mathrm{C}$ are $7,1.5^{\circ}, 0.7^{\circ}, 0.057,0.95,4.8 \%$, and 12.4 , respectively, verifying that every value satisfies the seven paleointensity selection criteria.

Figure 4 shows examples of the Arai plot for rejected paleointensity results. Figure 4(a) displays an example of a sample that exhibits non-linear and zigzag patterns of 

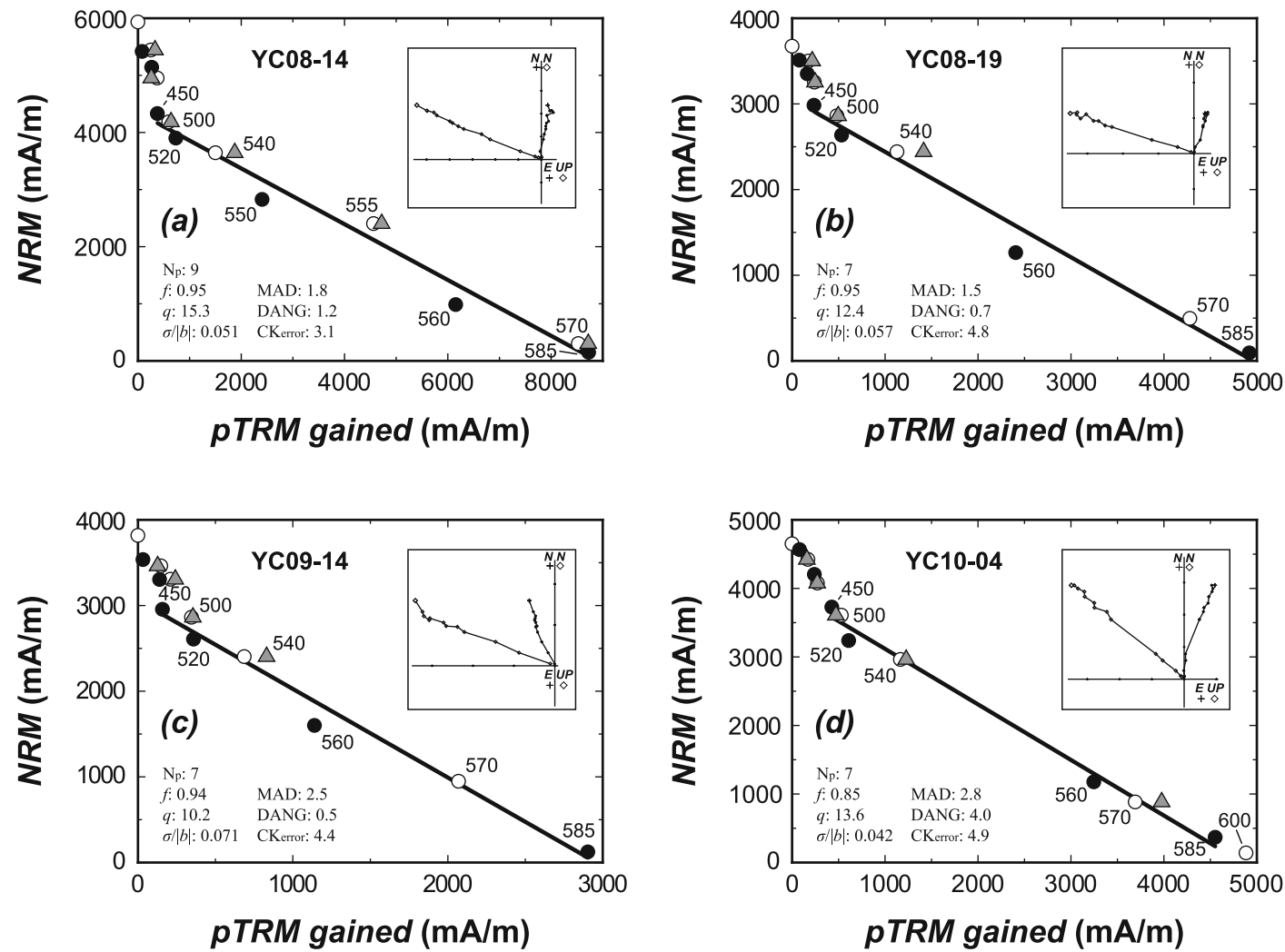

Fig. 3. Representative Arai plots of accepted samples from $(\mathrm{a}-\mathrm{c})$ the lava flows and $(\mathrm{d})$ the massive basalts observed in the IZZI experiment. Insets show the associated thermal demagnetization behavior for each sample. Solid and open circles indicate the results from in-field/zero-field (IZ) and zero-field/in-field (ZI) procedures, respectively. Triangles represent pTRM checks. Solid lines are the best-fit lines for the selected temperature intervals. Numbers beside solid and open circles show the corresponding temperature $\left({ }^{\circ} \mathrm{C}\right)$ of each heating step.
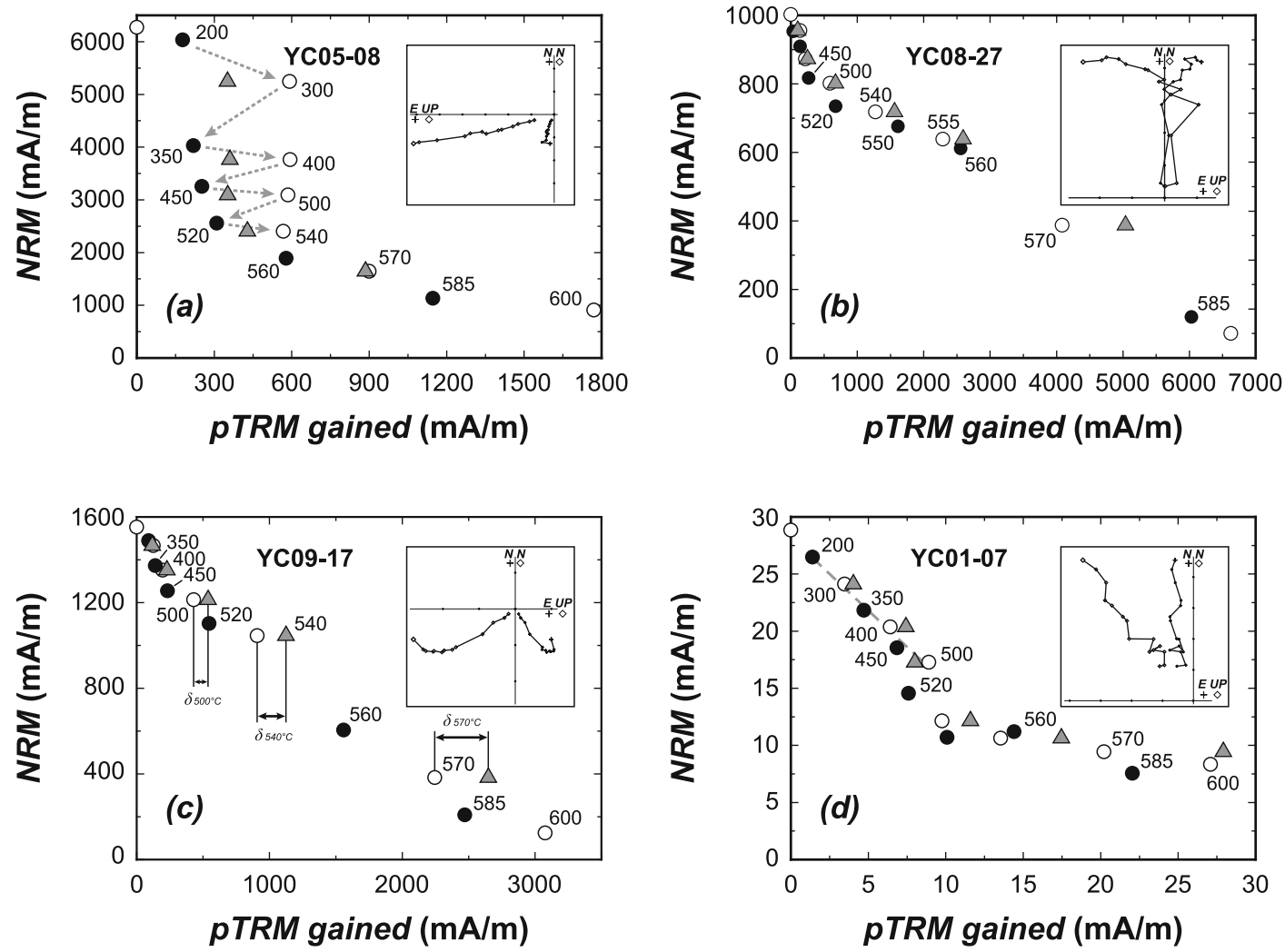

Fig. 4. Representative Arai plots of rejected samples from (a-c) the lava flows and (d) the massive basalts observed in the IZZI experiment. The dashed arrows in Fig. 4(a) represent a pronounced zigzag pattern on the Arai plot, and the pTRM check ranges $\left(\delta_{\text {temperature step }}\right)$ in Fig. 4(c) show the difference of the pTRM gained between the pTRM check and the pTRM at the same temperature. Descriptions of the other symbols are given in Fig. 3 . 
Table 2. Paleointensity results obtained from basalts in Yeoncheon.

\begin{tabular}{|c|c|c|c|c|c|c|c|c|c|c|c|c|}
\hline \multirow{2}{*}{ Site } & \multirow{2}{*}{ Sample } & \multirow{2}{*}{$\begin{array}{c}T_{\min }-T_{\max } \\
\left({ }^{\circ} \mathrm{C}\right)\end{array}$} & \multicolumn{7}{|c|}{ Paleointensity selection criteria ${ }^{a}$} & \multirow{2}{*}{$\begin{array}{c}\mathrm{B} \\
(\mu \mathrm{T})\end{array}$} & \multirow{2}{*}{$\begin{array}{c}\mathrm{B}_{\mathrm{m}} \pm \sigma_{\mathrm{m}} \\
(\mu \mathrm{T})\end{array}$} & \multirow{2}{*}{$\begin{array}{c}\mathrm{VADM}_{\mathrm{m}} \pm \sigma_{\mathrm{m}} \\
\left(10^{22} \mathrm{Am}^{2}\right)\end{array}$} \\
\hline & & & $\mathrm{N}_{\mathrm{p}}$ & MAD & DANG & $\sigma /|b|$ & $f$ & $\mathrm{CK}_{\text {error }}$ & $q$ & & & \\
\hline & \multicolumn{12}{|c|}{ Lava flows } \\
\hline \multirow[t]{4}{*}{ YC05 } & $05-17$ & $450-585$ & 9 & 2.1 & 1.5 & 0.069 & 0.97 & 1.5 & 11.9 & 13.4 & $13.1 \pm 4.3$ & $2.3 \pm 0.8$ \\
\hline & $05-19$ & $520-585$ & 7 & 2.5 & 0.9 & 0.025 & 0.76 & 4.4 & 22.9 & 18.6 & & \\
\hline & $05-20$ & $450-585$ & 9 & 2.9 & 2.7 & 0.061 & 0.82 & 2.8 & 10.9 & 8.1 & & \\
\hline & $05-26$ & $450-585$ & 9 & 1.8 & 3.4 & 0.069 & 0.88 & 3.3 & 10.6 & 12.4 & & \\
\hline \multirow[t]{3}{*}{ YC07 } & $07-20$ & $450-585$ & 9 & 1.9 & 0.9 & 0.058 & 0.93 & 2.0 & 12.7 & 15.5 & $18.6 \pm 3.3$ & $3.3 \pm 0.6$ \\
\hline & $07-21$ & $450-585$ & 9 & 1.7 & 0.2 & 0.072 & 0.98 & 3.7 & 11.1 & 18.3 & & \\
\hline & $07-26$ & $450-585$ & 9 & 2.2 & 0.4 & 0.074 & 0.91 & 4.3 & 10.2 & 22.0 & & \\
\hline \multirow[t]{2}{*}{ YC08 } & $08-14$ & $450-585$ & 9 & 1.8 & 1.2 & 0.051 & 0.95 & 3.1 & 15.3 & 12.3 & $13.9 \pm 2.2$ & $2.5 \pm 0.4$ \\
\hline & 08-19 & $450-585$ & 7 & 1.5 & 0.7 & 0.057 & 0.95 & 4.8 & 12.4 & 15.5 & & \\
\hline \multirow[t]{5}{*}{ YC09 } & 09-02 & $450-585$ & 9 & 4.3 & 4.9 & 0.069 & 0.85 & 3.3 & 10.1 & 8.4 & $21.3 \pm 8.5$ & $3.8 \pm 1.5$ \\
\hline & $09-13$ & $450-585$ & 9 & 3.6 & 1.8 & 0.069 & 0.85 & 3.9 & 10.6 & 17.1 & & \\
\hline & 09-14 & $450-585$ & 7 & 2.5 & 0.5 & 0.071 & 0.94 & 4.4 & 10.2 & 25.9 & & \\
\hline & $09-21$ & $450-585$ & 9 & 2.8 & 0.9 & 0.059 & 0.81 & 3.7 & 11.1 & 29.0 & & \\
\hline & 09-29 & $450-585$ & 7 & 2.4 & 0.4 & 0.059 & 0.93 & 3.9 & 12.0 & 26.1 & & \\
\hline \multirow[t]{2}{*}{ YC10 } & $10-04$ & $450-585$ & 7 & 2.8 & 4.0 & 0.042 & 0.85 & 4.9 & 13.6 & 20.4 & 20.4 & 3.6 \\
\hline & & & & & & & & & & Mean: & $17.5 \pm 3.7$ & $3.1 \pm 0.7$ \\
\hline
\end{tabular}

$T_{\min }-T_{\max }$ : the temperature interval used for paleointensity determination on the Arai plot; $\mathrm{B}$ : paleointensity estimate for individual samples; $\mathrm{B}_{\mathrm{m}} \pm$ $\sigma_{\mathrm{m}}$ : mean paleointensity value for individual sites and its standard deviation; $\mathrm{VADM}_{\mathrm{m}} \pm \sigma_{\mathrm{m}}$ : virtual axial dipole moment for individual sites and its standard deviation.

a A summary of paleointensity selection criteria is given in Table 1.

data points on the Arai plot with a high $\sigma /|b|(=0.492)$ and $\mathrm{CK}_{\text {error }}(=8.1 \%)$ at relatively low temperature steps $\left(200-540^{\circ} \mathrm{C}\right)$. This result is probably caused by a difference in the capacity for acquiring TRMs between the IZ and ZI procedures (Yu et al., 2004; Yu and Tauxe, 2005). Figure 4(b) provides an example of unstable remanence direction $\left(\mathrm{MAD}=22^{\circ}\right.$ and $\left.\mathrm{DANG}=18.4^{\circ}\right)$ with a failed pTRM check $\left(\mathrm{CK}_{\text {error }}=11.2 \%\right)$ at the high temperature interval of $450-585^{\circ} \mathrm{C}$, despite a linear trend $(\sigma /|b|$ $=0.054$ ). On the vector diagram (inset in Fig. 4(b)) in particular, the remanence exhibits unstable demagnetizing behavior from $550^{\circ} \mathrm{C}$ to $585^{\circ} \mathrm{C}$ with a high angular deviation $\left(\mathrm{MAD}=16.7^{\circ}\right)$. Consequently, experimental results showing this behavior are rejected, though data points at the high temperature interval $\left(450-585^{\circ} \mathrm{C}\right)$ are sufficiently linear to determine an acceptable paleointensity value. Figure 4(c) shows the importance of the pTRM checks; if there were no checks during the paleointensity experiments, there would be no other grounds for rejection. In the temperature steps above $500^{\circ} \mathrm{C}$, the pTRMs increase gradually (i.e., $\mathrm{CK}_{\text {error }\left(540^{\circ} \mathrm{C}\right)}=6.7 \%$ and $\mathrm{CK}_{\operatorname{error}\left(570^{\circ} \mathrm{C}\right)}=12.5 \%$, Fig. 4(c)). Finally, Fig. 4(d) is an example of samples showing a short linear trend of data points on the Arai plot $(f=0.39)$ at a low temperature interval $\left(200-500^{\circ} \mathrm{C}\right)$. Although a linear segment exists at the low temperature interval (grey dashed line), the remanence with a low unblocking temperature is likely to be contaminated by viscous remanent magnetization. In addition, the remanence direction is unstable above $500^{\circ} \mathrm{C}$ (inset of Fig. 4(d)) and accompanied by failed pTRM checks $\left(\mathrm{CK}_{\text {error }}=9.5 \%\right)$.

Of the 314 samples, 15 from the lava flows passed all seven criteria (Table 2). These samples demonstrate a negligible effect of remanence anisotropy $(<0.2 \%)$ because the correlation coefficient $\left(\mathrm{R}^{2}\right)$ of the estimated paleointensities before and after anisotropy correction for eight data points was 0.99 at the slope of unity. Accordingly, the correction was not applied to the paleointensity values in Table 2, even though details are not shown here. Consequently, the success rate for paleointensity determination in this study is $\sim 5 \%$. Such a low success rate is probably a result of the stringent paleointensity selection criteria, as well as the absence of artificial pre-selection of samples suitable for paleointensity experiments. In this study, the critical criteria for paleointensity determination are $q$ and $\mathrm{CK}_{\text {error }}$ since $\sim 82 \%$ (258 samples) and $\sim 71 \%$ (222 samples) of the rejected samples show $q<10$ and $\mathrm{CK}_{\text {error }}>5 \%$, respectively. In particular, 44 samples are rejected by either $q$ or $\mathrm{CK}_{\mathrm{error}}$, while satisfying the other six criteria. The sitemean paleointensities range from $13.1 \mu \mathrm{T}$ to $21.3 \mu \mathrm{T}$, with the mean for the lava flows of $17.5 \pm 3.7 \mu \mathrm{T}$ (Table 2).

\section{Rock-magnetic Properties}

\subsection{Magnetic mineralogy}

According to the results from the stepwise thermal demagnetization of 3-axis IRM (Fig. 5(a-c)) and the $k-T$ curve (Fig. 5(d-f)), samples can be classified into three distinctive types. The samples belonging to the first type (the left panels of Fig. 5) are characterized by a predominance of low-coercivity $(<0.12 \mathrm{~T})$ components. The remanences drop significantly at $\sim 540^{\circ} \mathrm{C}$ and are completely unblocked at $\sim 580^{\circ} \mathrm{C}$ (Fig. $5(\mathrm{a})$ ). On the $k-T$ curve, this type demonstrates an almost reversible trend between the heating and cooling curves throughout the experiment, with a $T_{\mathrm{c}}$ comparable to Ti-poor titanomagnetite (Fig. 5(d)). Twenty-one samples from the lava flows and four samples from the massive basalts correspond to the first type. In the case of the second type (the central panels of Fig. 5), low-coercivity components are removed entirely at $\sim 580-600^{\circ} \mathrm{C}$, while 

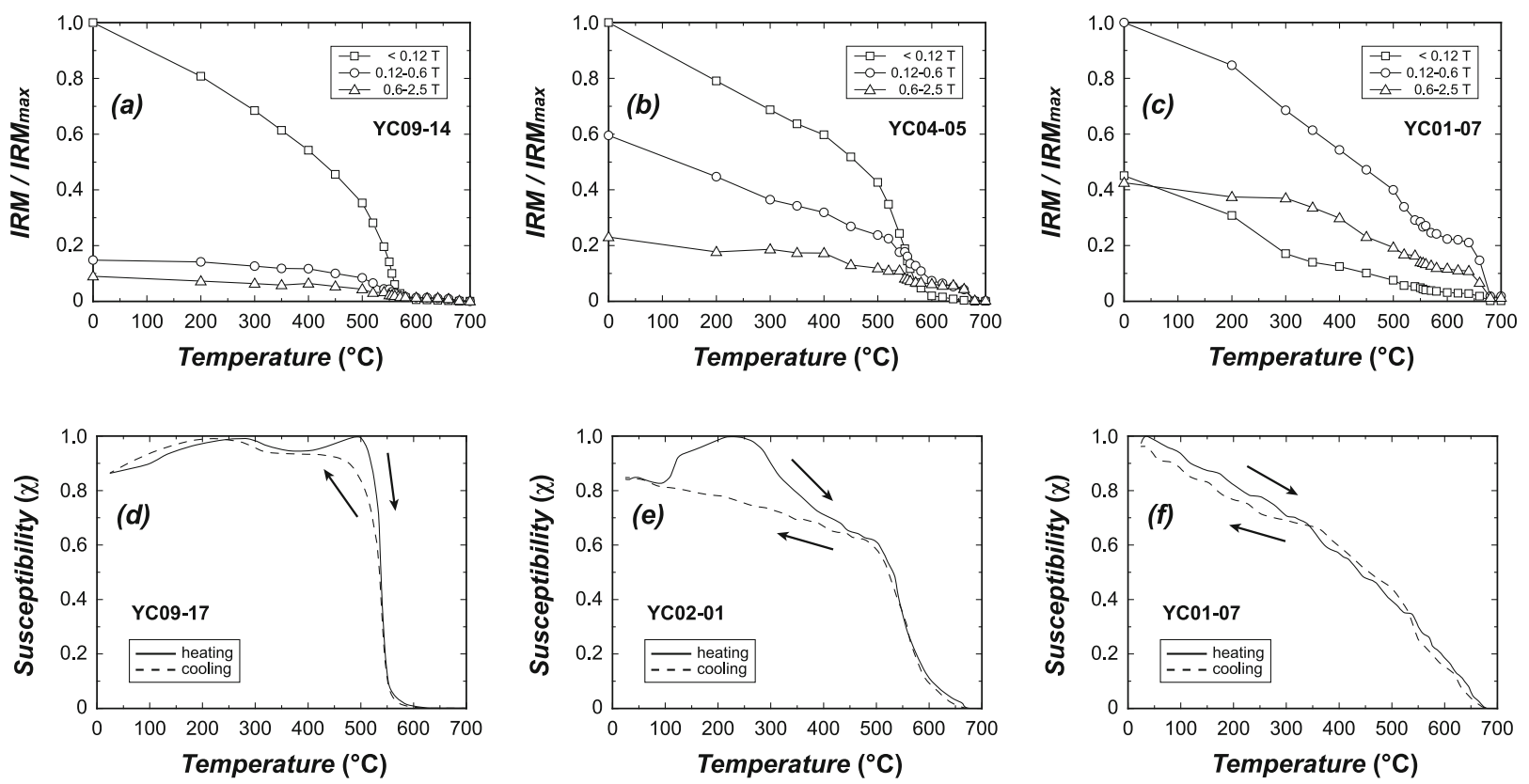

Fig. 5. (a-c) Representative results of the thermal demagnetization of 3-axis isothermal remanent magnetization. Squares, circles, and triangles represent low- $(<0.12 \mathrm{~T})$, intermediate- $(=0.12-0.6 \mathrm{~T})$, and high-coercivity $(=0.6-2.5 \mathrm{~T})$ components, respectively. $(\mathrm{d}-\mathrm{f})$ Temperature dependence of the magnetic susceptibility $(k-T)$ curves for selected samples.

intermediate- and high-coercivity components both unblock at $\sim 580^{\circ} \mathrm{C}$ and $\sim 680^{\circ} \mathrm{C}$ (Fig. 5(b)). Similarly, a significant susceptibility drop occurs at $\sim 540-570^{\circ} \mathrm{C}$, followed by a gradual decrease in susceptibility up to $\sim 680^{\circ} \mathrm{C}$ on the $k-T$ curve (Fig. 5(e)). This indicates that samples of the second type are composed of both (titano)magnetite and hematite. Finally, the third type (the right panels of Fig. 5) shows that all of the coercivity components are gradually demagnetized up to $\sim 640^{\circ} \mathrm{C}$ and then unblocked at $\sim 680^{\circ} \mathrm{C}$ (Fig. 5(c)). The $k-T$ curve also shows a gradual decrease in susceptibility up to $680^{\circ} \mathrm{C}$ (Fig. 5(f)). Such behavior can be attributed to the predominance of hematite. The second and third types of behavior are only observed in eight samples from the massive basalts. Results of the thermal demagnetization of 3-axis IRMs and $k-T$ curves indicate that (titano)magnetite is the major magnetic phase in the lava flows. On the other hand, hematite or hematite with (titano)magnetite is dominant in the massive basalts.

\subsection{Magnetic granulometry}

To identify the domain state of (titano)magnetite in samples from the lava flows, the values of $M_{\mathrm{rs}} / M_{\mathrm{s}}$ and $B_{\mathrm{cr}} / B_{\mathrm{c}}$ are presented with theoretical curves (Dunlop, 2002) for mixtures of single-domain (SD) and superparamagnetic (SP) particles as well as SD and multi-domain (MD) grains on a Day plot (Day et al., 1977) in Fig. 6. Although samples from the massive basalts contain hematite, results from the massive basalts are also shown for comparison. Except for some samples from the massive basalts, the lava flow samples are aligned closely to the SD-SP mixture curve or occupy the pseudo-single-domain (PSD) region, indicating a negligible contribution of MD particles. In particular, every sample for which paleointensity determination was successful is on the SD-SP curve with relative volume fractions of $\sim 75-90 \%$ SD particles and $\sim 10-25 \%$ SP grains. This result indicates that, for our samples, the dominance of SD behavior increases the likelihood of success in our paleointensity experiments.

\section{Scanning Electron Microscope Observation}

The magnetic minerals in the observed samples are revealed as iron oxides, occasionally with the addition of a small amount of Ti. Depending on whether or not paleointensity was able to be determined, these iron oxides are characterized by variable grain-size distribution and composition. The upper panels in Fig. 7 show representative backscattered electron (BSE) images of iron oxides in samples that yielded successful paleointensity results. Anhedral to subhedral iron oxides of $\sim 1-2 \mu \mathrm{m}$ in length are predominant (Fig. 7(a, b)), with few of these iron oxides accompanied by ilmenite lamellae (i.e., they lack the oxyexsolution of titanomagnetite). The shape, size, and texture of the particles indicate that most of the samples accepted in paleointensity determination may have cooled rapidly after the crystallization of iron oxides at high temperatures above the titanomagnetite solvus (Haggerty, 1976). On the other hand, iron oxides in a few samples from the lava flows had an exsolution texture with ilmenite lamellae (Fig. 7(c)). Clear compositional separation commonly results from the deuteric oxidation of titanomagnetite during the initial cooling period after it melts (e.g., Kent et al., 1978; Biggin et al., 2007). In addition, deuteric oxidation has a positive effect on paleointensity experiments because the effective particle size of iron oxides decreases close to a SD bounded by ilmenite lamellae. Variation in the texture of the iron oxides indicates that the lava flows in the study area cooled under different conditions. The existence of two types of iron oxide can probably be attributed to differences in the thickness of the lava layers. Most iron oxides with ilmenite lamellae appear in samples taken from relatively thick lava layers, while iron oxides without ilmenite lamellae are ob- 


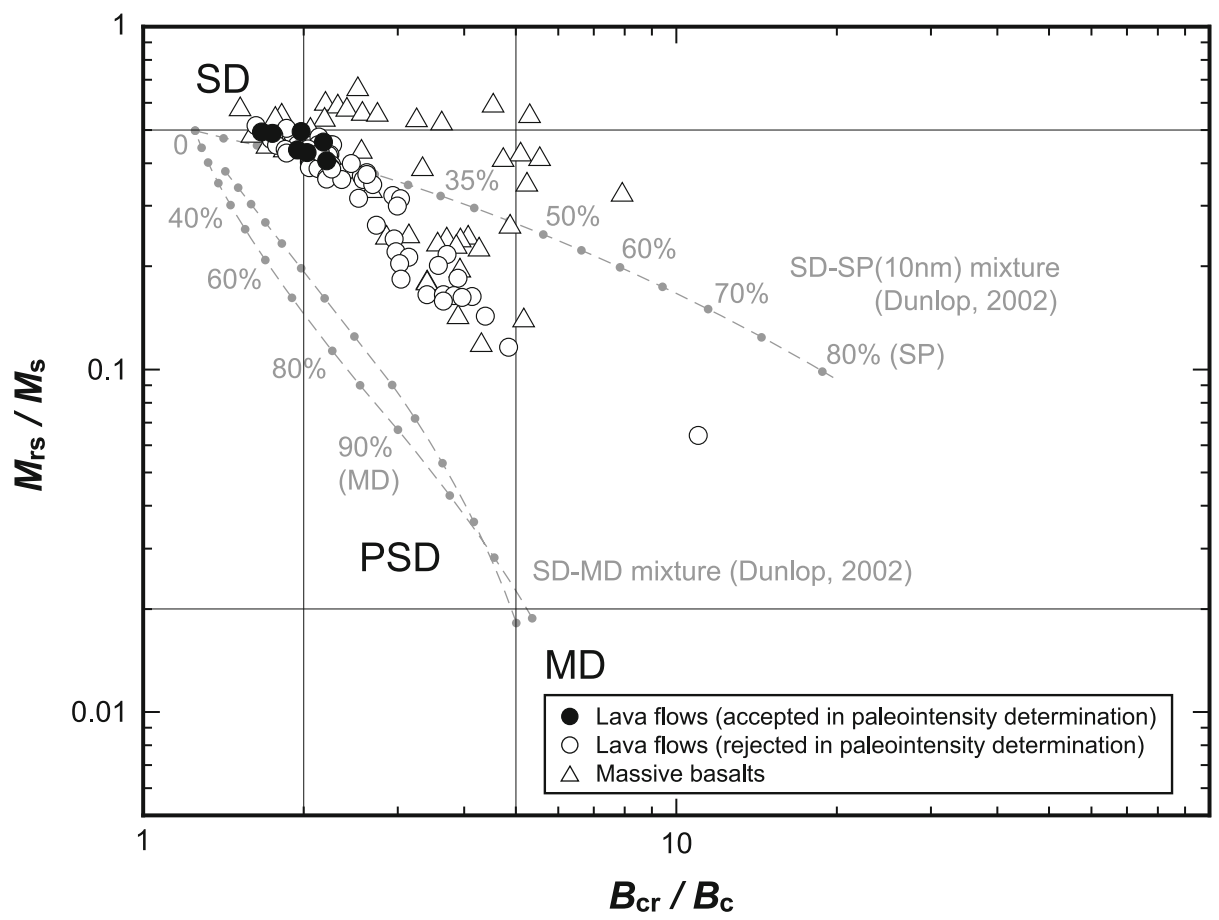

Fig. 6. Plot of hysteresis ratios $\left(M_{\mathrm{rs}} / M_{\mathrm{S}}\right.$ and $\left.B_{\mathrm{cr}} / B_{\mathrm{c}}\right)$ (Day plot; Day et al., 1977) representing the dominant domain states of magnetic minerals within the samples. Single-domain (SD), multi-domain (MD), and superparamagnetic (SP) mixing lines of Dunlop (2002) are shown in grey. Numbers alongside the curves are volume fractions of SP or MD particles present in mixtures with SD grains.
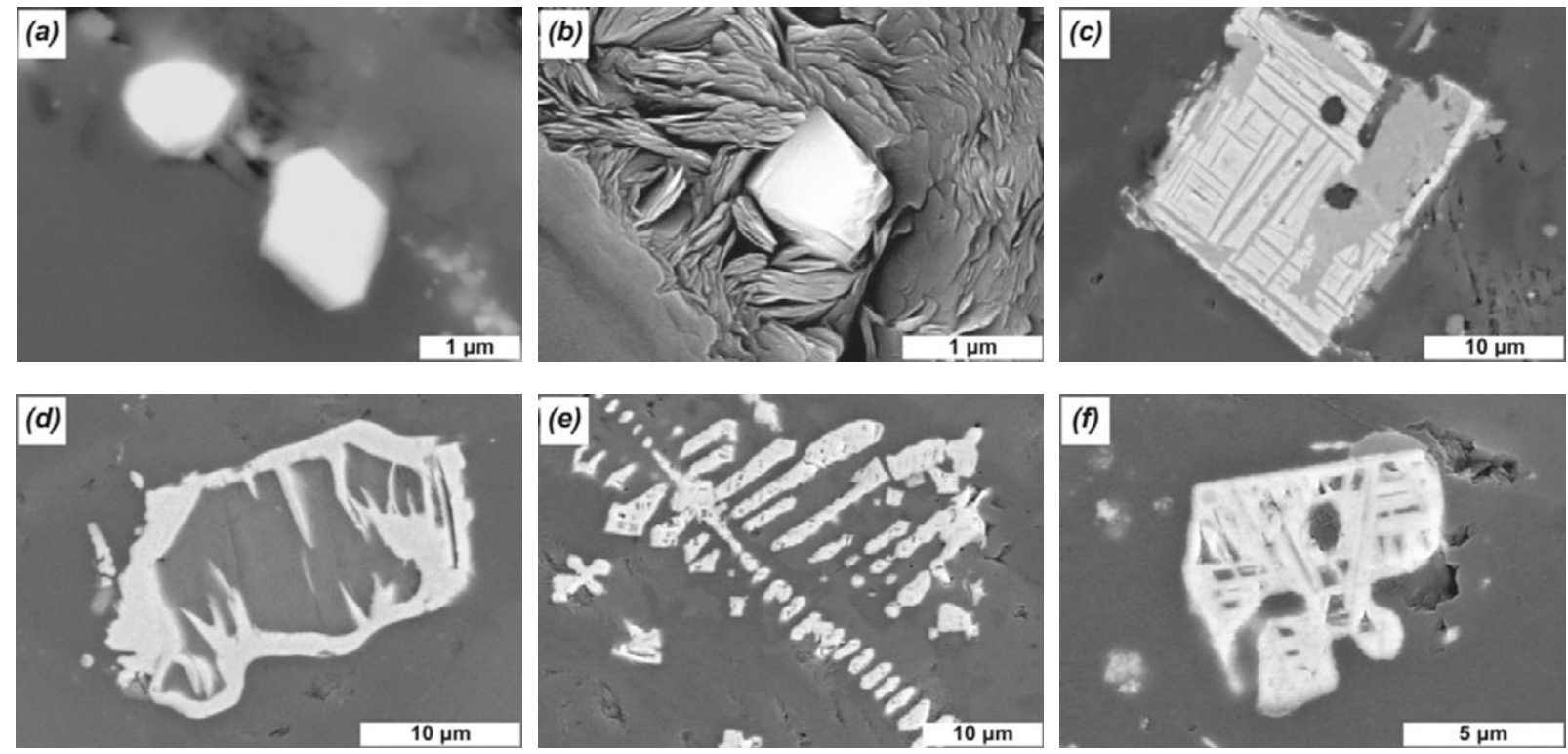

Fig. 7. Representative scanning electron microscope images of polished sections for (a-c) accepted and (d-f) rejected samples in paleointensity determination. (a, c, and d) Backscattered electron (BSE) images for frequently observed iron oxides in samples from the lava flows showing (a) anhedral to subhedral iron oxides, (c) ilmenite lamellae, and (d) a thick rim of iron oxide reflecting secondary alteration. (b, e, and f) BSE images of iron oxides in samples from the massive basalts showing (e) dendritic and cruciform iron oxides, and (f) a trellis texture.

served in samples collected from either thin lava layers or the margin of thick lava layers.

The lower panels in Fig. 7 show BSE images of iron oxides from the samples rejected in paleointensity determination. For the rejected samples from the lava flows, the iron oxides are characterized by secondary precipitation forming rims of iron oxide surrounding iron-rich silicate minerals (e.g., olivine) with overall grain sizes of $\sim 20 \mu \mathrm{m}$ (Fig. 7(d)). Such a large grain size may negatively affect the chance of obtaining reliable paleointensity estimates. In the case of the massive basalts, iron oxides predominantly occur in dendritic and cruciform with grain sizes of $<10 \mu \mathrm{m}$ (Fig. 7(e)). In particular, iron oxide adjacent to voids has a trellis texture (Fig. 7(f)). This texture is typical of hematite pseudomorphed after magnetite (i.e., martite) when exposed to oxidizing conditions for long periods of time (e.g., Heider and Dunlop, 1987). The existence of hematite in samples from massive basalts has also been 


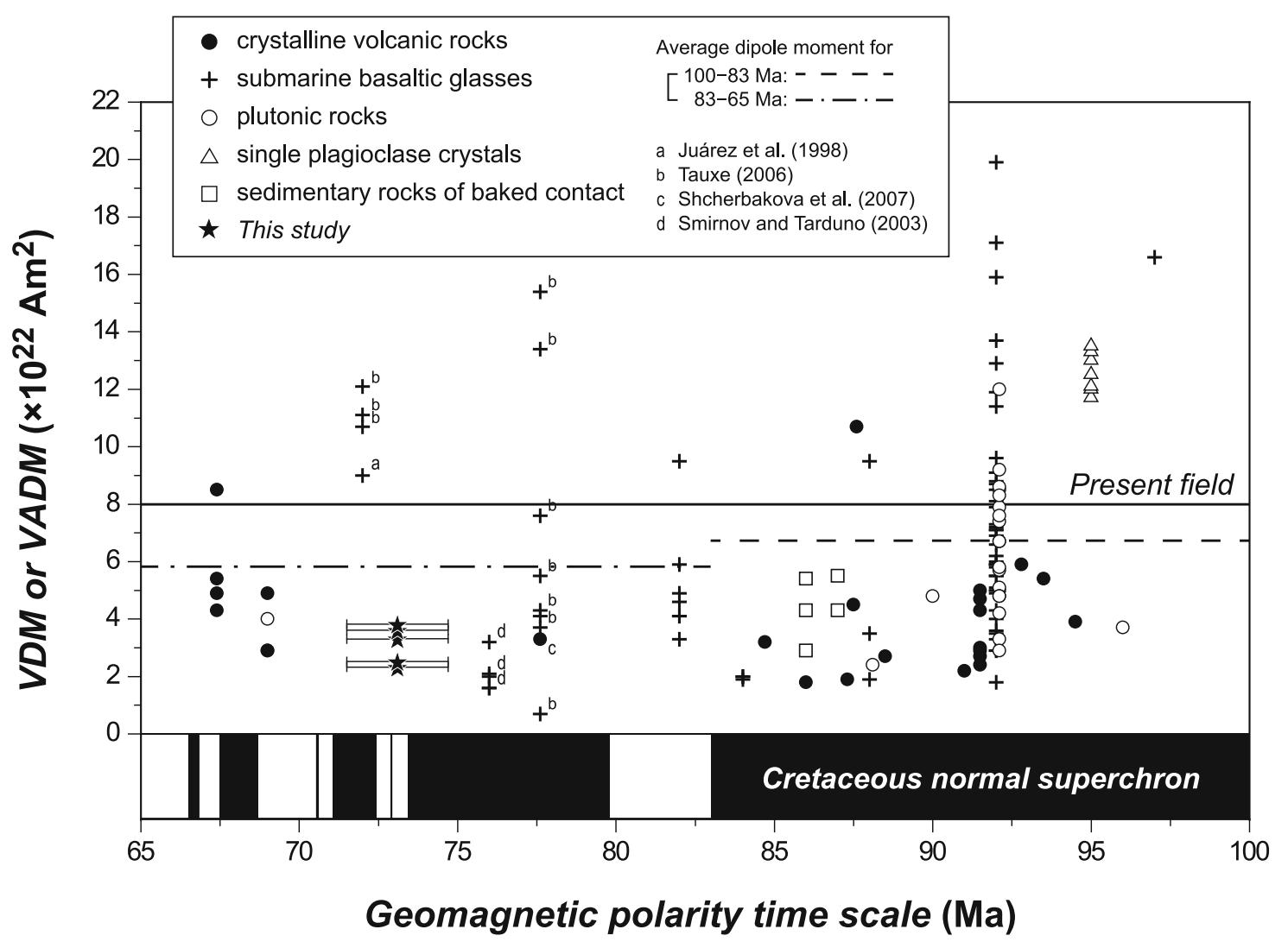

Fig. 8. Virtual (axial) dipole moments for the Late Cretaceous obtained from the PINT database. The solid horizontal line represents the strength of the present geomagnetic dipole moment. The geomagnetic polarity timescale based on Walker et al. (2012) is shown at the bottom of the figure.

observed in earlier rock-magnetic investigations. Consequently, it is possible that the samples that were failed in paleointensity determination suffered from magnetomineralogical alteration after cooling of the magmatic body or during thermal treatment in the paleointensity experiments.

Overall, observations using a scanning electron microscope reveal that the predominant magnetic phase in samples from the lava flows is Ti-poor titanomagnetite exhibiting a SD or PSD state, and which is expected to preserve primary remanent magnetization. In contrast, a considerable amount of the iron oxide in samples from the massive basalts suffers from secondary alteration. In particular, samples for which paleointensity was able to be determined are dominated by SD (titano)magnetite, observed in anhedral to subhedral form.

\section{Paleointensity during the Late Cretaceous}

It is known that the geometry of the Earth's magnetic field has been predominantly dipolar for at least the past 250 Myr (e.g., Bloxham, 2000). Therefore, the measured intensity of the geomagnetic field should be expected to vary depending on geographic location. To compare the field intensities from various regions, an estimated paleofield should be converted into a virtual dipole moment (VDM) using magnetic paleolatitude derived from mean inclination (Smith, 1967). When directional information is uncertain, a VDM can be substituted with a virtual axial dipole moment (VADM) using the site latitude or estimated paleolatitudes from an apparent polar wander path (Barbetti et al., 1977). In the present study, we calculate a VADM instead of a VDM using the current latitude of the sampling sites, based on previous paleomagnetic results (Doh and Piper, 1994; Zhao et al., 1999; Doh et al., 2002; Kim et al., 2009) suggesting that the Korean Peninsula experienced clockwise rotation around its vertical axis with respect to Eurasia until the early Paleogene without significant latitudinal movement (i.e., a possible latitudinal difference of $\left.<0.5^{\circ}\right)$.

Site-mean paleointensities from the Late Cretaceous basalts in this study are $13.1-21.3 \mu \mathrm{T}$, equivalent to calculated VADMs of 2.3-3.8 $\times 10^{22} \mathrm{Am}^{2}$. Considered in conjunction with the radiometric age of the lava flows, the mean VADM with its standard deviation for the times $\sim 73.1 \mathrm{Ma}$ is determined to be $3.1 \pm 0.7 \times 10^{22} \mathrm{Am}^{2}$ (stars in Fig. 8), which corresponds to $\sim 40 \%$ of the present geomagnetic axial dipole moment $\left(=\sim 8.0 \times 10^{22} \mathrm{Am}^{2}\right)$. Calculating a single paleointensity estimate ( $\mathrm{YC10-04)}$ from the sampling site YC10 (Table 2) may be considered insufficient to represent the paleointensity for an entire site, but the sample satisfies all seven criteria and demonstrates a suitably linear trend on the Arai plot (Fig. 3(d)). Therefore, the paleointensity data from YC10 is not excluded from the analysis of Late Cretaceous paleointensity.

In order to provide details for the paleointensity behavior during the Late Cretaceous (100-65 Ma), the six sitemean paleointensities in this study are compared with previously published paleointensity data archived in the 2012 version of the PINT database. Of the $>250$ entries from the 
Table 3. Mean virtual (axial) dipole moment during the Late Cretaceous for each rock type.

\begin{tabular}{|c|c|c|c|}
\hline $\begin{array}{l}\text { Age interval } \\
\text { (Ma) }\end{array}$ & $\mathrm{N}$ & $\begin{array}{l}\text { VDM or VADM } \\
\left(\times 10^{22} \mathrm{Am}^{2}\right)\end{array}$ & References \\
\hline \multicolumn{4}{|c|}{ Crystalline volcanic rock ${ }^{\mathrm{a}}$} \\
\hline $100-83$ & $17(13)$ & $4.0 \pm 2.1(4.3 \pm 2.3)$ & {$[1]-[5]$} \\
\hline $83-65$ & $13(5)$ & $4.0 \pm 1.6(4.2 \pm 0.9)$ & {$[5],[16],[17]$, this study } \\
\hline \multicolumn{4}{|c|}{ Submarine basaltic glass } \\
\hline $100-83$ & $47(31)$ & $7.2 \pm 4.3(7.3 \pm 4.0)$ & {$[6]-[9]$} \\
\hline $83-65$ & $19(3)$ & $7.1 \pm 4.0(6.5 \pm 2.2)$ & {$[6],[7]$} \\
\hline \multicolumn{4}{|c|}{ Plutonic rocks (gabbro and dolerite) } \\
\hline $100-83$ & $22(20)$ & $6.2 \pm 2.4(6.4 \pm 2.3)$ & {$[10]-[12]$} \\
\hline $83-65$ & $1(-)$ & $(-)$ & {$[16]$} \\
\hline \multicolumn{4}{|c|}{ Single plagioclase crystal } \\
\hline $100-83$ & $8(8)$ & $12.7 \pm 0.7(12.7 \pm 0.7)$ & [13] \\
\hline $83-65$ & $-(-)$ & $-(-)$ & - \\
\hline \multicolumn{4}{|c|}{ Sedimentary rocks of baked contact } \\
\hline $100-83$ & $5(4)$ & $4.5 \pm 1.1(4.9 \pm 0.7)$ & {$[14],[15]$} \\
\hline $83-65$ & $-(-)$ & $-(-)$ & - \\
\hline \multicolumn{4}{|c|}{ All rock types } \\
\hline $100-83$ & $99(76)$ & $6.7 \pm 3.9(7.0 \pm 3.7)$ & {$[1]-[15]$} \\
\hline $83-65$ & $33(8)$ & $5.8 \pm 3.5(5.1 \pm 1.8)$ & {$[5]-[7],[16],[17]$, this study } \\
\hline
\end{tabular}

$\mathrm{N}$ : the number of cooling units used in calculating mean virtual (axial) dipole moment. The values in parentheses are calculated from a more rigorously selected paleointensity data set (see text for details). [1] Sherwood et al. (1993), [2] Tanaka and Kono (2002), [3] Zhao et al. (2004), [4] Riisager et al. (2001), [5] Shcherbakova et al. (2007), [6] Tauxe (2006), [7] Juárez et al. (1998), [8] Tauxe and Staudigel (2004), [9] Pick and Tauxe (1993), [10] Shcherbakova et al. (2012), [11] Granot et al. (2007), [12] Thomas et al. (2000), [13] Tarduno et al. (2002), [14] Shcherbakova et al. (2008), [15] Shcherbakova et al. (2009), [16] Perrin et al. (1999), [17] Goguitchaichvili et al. (2004).

${ }^{a}$ Crystalline volcanic rock excludes submarine basaltic glass, even though basaltic glass occasionally includes crystalline particles (e.g., SD magnetite).

database, 132 data sets from 18 different studies were selected for comparison. The selected data were all obtained using the Thellier-type method with pTRM checks, and were unrelated to a geomagnetic polarity transition. Figure 8 shows the selected Late Cretaceous VDMs or VADMs alongside our data. Four previously reported studies (Juárez et al., 1998; Smirnov and Tarduno, 2003; Tauxe, 2006; Shcherbakova et al., 2007) have investigated basalts of a similar age to those in this study $(\sim 80-70 \mathrm{Ma})$. Basalts from $\sim 77.6 \mathrm{Ma}$ in Georgia (Shcherbakova et al., 2007) had a VDM of $3.3 \pm 0.1 \times 10^{22} \mathrm{Am}^{2}$, consistent with the VADMs $\left(=2.3-3.8 \times 10^{22} \mathrm{Am}^{2}\right)$ of this study. In contrast to the stable VDMs reported from basalts, results from SBG of $\sim 77.6 \mathrm{Ma}$ (Tauxe, 2006), $76 \mathrm{Ma}$ (Smirnov and Tarduno, 2003), and 72 Ma (Juárez et al., 1998; Tauxe, 2006) reveal a mean VDM of $6.8 \pm 5.1 \times 10^{22} \mathrm{Am}^{2}, 2.1$ $\pm 0.7 \times 10^{22} \mathrm{Am}^{2}$, and $10.7 \pm 1.3 \times 10^{22} \mathrm{Am}^{2}$, respectively. Such a high fluctuation could be caused by the locking process of the geomagnetic field in SBG, which can cool too fast and thus not average out the secular variation. Some studies (e.g., Heller et al., 2002; Bowles et al., 2011) also argue that SBG is suspected to be altered during thermal treatments above $300^{\circ} \mathrm{C}$. Indeed, Smirnov and Tarduno (2003) reported that their VDMs were under-estimated due to high temperature (above $350-400^{\circ} \mathrm{C}$ ) mineral alteration. The VDMs of Smirnov and Tarduno (2003) are thus excluded from the paleointensity analysis of the Late Cretaceous.

Paleointensity during the Late Cretaceous according to rock type was compared with the mean dipole moment for two different time intervals bound by $83 \mathrm{Ma}$. The intervals are delimited based on the end of the CNS. The calculated mean dipole moment for each time interval and rock type is summarized in Table 3. For reference, crystalline volcanic rock excludes SBG, even though basaltic glass occasionally includes crystalline particles (e.g., SD magnetite). According to the results from crystalline volcanic rock, the mean dipole moment for the later part of the CNS (100-83 Ma) is $4.0 \pm 2.1 \times 10^{22} \mathrm{Am}^{2}$, almost the same as the average dipole moment for the period 5-160 Ma $(=4.2 \pm 2.3 \times$ $10^{22} \mathrm{Am}^{2}$; Juárez et al., 1998). After the CNS, dipole moments $\left(=4.0 \pm 1.6 \times 10^{22} \mathrm{Am}^{2}\right)$ for the period $83-65 \mathrm{Ma}$ did not change significantly, remaining almost constant (Table 3). Similarly, no time-dependent variation is observed in the mean dipole moment for the data obtained using SBG (Table 3). However, SBG stands out for its relatively high mean dipole moment and large error range, estimated to be approximately two times higher than that found in crys- 
talline volcanic rock $\left(=7.2 \pm 4.3 \times 10^{22} \mathrm{Am}^{2}\right.$ for $100-83$ $\mathrm{Ma} ;=7.1 \pm 4.0 \times 10^{22} \mathrm{Am}^{2}$ for $83-65 \mathrm{Ma}$; Table 3 )

Dipole moments from plutonic rocks in the Late Cretaceous are also documented in the PINT database. For the period of 100-83 Ma, the mean dipole moment is calculated to be $6.2 \pm 2.4 \times 10^{22} \mathrm{Am}^{2}$, which corresponds to a value between the mean dipole moments of crystalline volcanic rock and SBG. For the period of 83-65 Ma, only a single $\operatorname{VDM}\left(=4.0 \times 10^{22} \mathrm{Am}^{2}\right)$ is reported from Perrin et al. (1999), and accord with the mean dipole moment obtained from crystalline volcanic rock (Table 3 ). As the cooling rate of plutonic rock is much slower than during laboratory cooling, correction for the cooling rate is required (e.g., Dodson and McClelland-Brown, 1980; Fox and Aitken, 1980; Halgedahl et al., 1980; Walton and Williams, 1988). However, a commonly applied correction method has not yet been established.

Additional data from single plagioclase crystals (VDM of $\sim 95 \mathrm{Ma}=12.7 \pm 0.7 \times 10^{22} \mathrm{Am}^{2}$; Tarduno et al., 2002) and from sedimentary rock of baked contact (VDM of $\sim 86.4 \mathrm{Ma}=4.5 \pm 1.1 \times 10^{22} \mathrm{Am}^{2}$; Shcherbakova $e t$ al., 2008, 2009) are available within the time interval of 100-83 Ma (Table 3) in the PINT database. The mean VDM from single plagioclase crystals is almost three times higher than that from crystalline volcanic rock $(=4.0 \pm$ $2.1 \times 10^{22} \mathrm{Am}^{2}$ ), while the mean VDM from sedimentary rock of baked contact is comparable to that from crystalline volcanic rock. However, the absence of paleointensity data from single plagioclase crystals and sedimentary rock in the later part of the Late Cretaceous (83-65 Ma) makes it difficult to discuss overall geomagnetic field variation during the Late Cretaceous.

The mean dipole moments of entire rock types $(=6.7 \pm$ $3.9 \times 10^{22} \mathrm{Am}^{2}$ for $100-83 \mathrm{Ma} ;=5.8 \pm 3.5 \times 10^{22} \mathrm{Am}^{2}$ for 83-65 Ma) are also higher than that of crystalline volcanic rock, which is caused by the higher values from SBG, plutonic rock, and single plagioclase crystals. Nevertheless, the dipole moments are lower than the present field strength (Table 3). It is obvious that there exists a degree of variability when comparing different materials (e.g., compare crystalline rock, SBG, or single plagioclase crystals during the 100-83 Ma period; Table 3). On the other hand, geomagnetic field intensity during the Late Cretaceous was relatively low and stable, when each material is considered separately or all materials are considered collectively. In order to check for consistency from a more rigorously selected data set, a second group of paleointensity data was selected from the PINT database by applying two additional criteria (e.g., Biggin et al., 2009): (1) at least three samples should be used to calculate the VDM or VADM; and (2) the standard deviation should not be greater than $25 \%$ of the mean paleointensity. The calculated mean dipole moments from the second group of paleointensity data for each time interval and rock type are given within parentheses in Table 3. When the two sets of mean dipole moments are compared, it is noticeable that little difference exists between them, and that the characteristic Late Cretaceous feature of a relatively low, stable geomagnetic field can also be found in the second data set (Table 3). Considering that the reversal rate started to increase after the CNS (Fig. 8), it can be speculated that the initiation of geomagnetic field reversal was triggered without significant changes in average paleofield strength (see Fig. 8 and Table 3). This interpretation is supported by Goguitchaichvili et al. (2004), who suggested that there is no relationship between reversal rate and the strength of the geomagnetic field.

\section{Conclusions}

In this study, absolute paleointensity values for Korean basalts dating from the Late Cretaceous-after the Cretaceous Normal Superchron (CNS) - are obtained. The estimated site-mean paleointensities range from 13.1 to 21.3 $\mu \mathrm{T}$, which corresponds to virtual axial dipole moments (VADMs) of 2.3-3.8 $\times 10^{22} \mathrm{Am}^{2}$. Based on the radiometric age of the basalts, the VADM for $\sim 73.1 \mathrm{Ma}$ is calculated to be $3.1 \pm 0.7 \times 10^{22} \mathrm{Am}^{2}$. According to the results of rockmagnetic investigations and scanning electron microscope observations, it is revealed that Ti-poor titanomagnetite (either SD or PSD grain size) is the major magnetic carrier in the lava flows, while hematite or hematite with magnetite is dominant in the massive basalts. In particular, samples for which paleointensity was able to be determined were predominantly composed of SD (titano)magnetite, observed in anhedral to subhedral form. A compilation of Late Cretaceous geomagnetic dipole moments obtained from crystalline volcanic rock and submarine basaltic glass had in common no significant time-dependent variation up until at least $65 \mathrm{Ma}$, regardless of geomagnetic field reversals. Based on this geomagnetic field behavior during the Late Cretaceous, it can be speculated that the initiation of geomagnetic field reversal after the CNS occurred without significant changes in average paleofield strength.

Acknowledgments. This research was supported by the Basic Science Research Program through the National Research Foundation of Korea (NRF), funded by the Ministry of Science, ICT and Future Planning (MSIP, 2011-0009679). This manuscript was greatly improved by constructive comments and suggestions by Dr. G. A. Paterson and an anonymous reviewer, as well as by the journal Editor Prof. T. Yamazaki.

\section{References}

Barbetti, M. F., M. W. McElhinny, D. J. Edwards, and P. W. Schmidt, Weathering processes in baked sediments and their effects on archaeomagnetic field-intensity measurements, Phys. Earth Planet. Inter., 13(4), 346-354, 1977.

Besse, J. and V. Courtillot, Apparent and true polar wander and the geometry of the geomagnetic field over the last $200 \mathrm{Myr}$, J. Geophys. Res. (Solid Earth), 107(B11), EPM6-1-EPM6-31, 2002.

Biggin, A. J., M. Perrin, and M. J. Dekkers, A reliable absolute palaeointensity determination obtained from a non-ideal recorder, Earth Planet. Sci. Lett., 257(3-4), 545-563, 2007.

Biggin, A. J., G. H. M. A. Strik, and C. G. Langereis, The intensity of the geomagnetic field in the late-Archaean: new measurements and an analysis of the updated IAGA palaeointensity database, Earth Planets Space, 61, 9-22, 2009.

Biggin, A. J., A. McCormack, and A. Roberts, Paleointensity database updated and upgraded, Eos Trans. AGU, 91(2), 15, 2010.

Bloxham, J., Sensitivity of the geomagnetic axial dipole to thermal coremantle interactions, Nature, 405, 63-65, 2000.

Bowles, J. A., J. S. Gee, K. Burgess, and R. F. Cooper, Timing of magnetite formation in basaltic glass: Insights from synthetic analogs and relevance for geomagnetic paleointensity analyses, Geochem. Geophys. Geosyst., 12(2), Q02001, doi:10.1029/2010GC003404, 2011.

Coe, R. S., S. Grommé, and E. A. Mankinen, Geomagnetic paleointensities from radiocarbon-dated lava flows on Hawaii and the question of the 
Pacific nondipole low, J. Geophys. Res. (Solid Earth), 83(B4), 17401756, 1978.

Day, R., M. Fuller, and V. A. Schmidt, Hysteresis properties of titanomagnetites: Grain-size and compositional dependence, Phys. Earth Planet. Inter., 13(4), 260-267, 1977.

Dodson, M. H. and E. McClelland-Brown, Magnetic blocking temperatures of single-domain grains during slow cooling, J. Geophys. Res. (Solid Earth), 85(B5), 2625-2637, 1980.

Doh, S.-J. and J. D. A. Piper, Palaeomagnetism of the (Upper PalaeozoicLower Mesozoic) Pyongan Supergroup, Korea: a Phanerozoic link with the North China Block, Geophys. J. Int., 117(3), 850-863, 1994.

Doh, S.-J., W. Kim, D. Suk, Y.-H. Park, and D. Cheong, Palaeomagnetic and rock-magnetic studies of Cretaceous rocks in the Gongju Basin, Korea: implication of clockwise rotation, Geophys. J. Int., 150(3), 737752, 2002.

Dunlop, D. J., Theory and application of the Day plot $\left(M_{\mathrm{rs}} / M_{\mathrm{S}}\right.$ versus $\left.H_{\mathrm{cr}} / H_{\mathrm{c}}\right) 1$. Theoretical curves and tests using titanomagnetite data, $J$. Geophys. Res. (Solid Earth), 107(B3), EPM4-1-EPM4-22, 2002.

Fox, J. M. W. and M. J. Aitken, Cooling-rate dependence of thermoremanent magnetization, Nature, 283, 462-463, 1980.

Gallet, Y. and G. Hulot, Stationary and nonstationary behaviour within the geomagnetic polarity time scale, Geophys. Res. Lett., 24(15), 18751878, 1997.

Glatzmaier, G. A., R. S. Coe, L. Hongre, and P. H. Roberts, The role of the Earth's mantle in controlling the frequency of geomagnetic reversals, Nature, 401, 885-890, 1999.

Goguitchaichvili, A., L. M. Alva-Valdivia, J. Rosas-Elguera, J. UrrutiaFucugauchi, and J. Solé Absolute geomagnetic paleointensity after the Cretaceous Normal Superchron and just prior to the CretaceousTertiary transition, J. Geophys. Res. (Solid Earth), 109, B01105, doi:10.1029/2003jb002477, 2004.

Granot, R., L. Tauxe, J. S. Gee, and H. Ron, A view into the Cretaceous geomagnetic field from analysis of gabbros and submarine glasses, Earth Planet. Sci. Lett., 256(1-2), 1-11, 2007.

Haggerty, S. E., Oxidation of opaque mineral oxides in basalts, in Oxide Minerals (Reviews in Mineralogy, Vol. 3), edited by D. Rumble, Hg1Hg100 pp., Mineral. Soc. America, Washington, D.C., 1976.

Halgedahl, S. L., R. Day, and M. Fuller, The effect of cooling rate on the intensity of weak-field TRM in single-domain magnetite, J. Geophys. Res. (Solid Earth), 85(B7), 3690-3698, 1980.

Heider, F. and D. J. Dunlop, Two types of chemical remanent magnetization during the oxidation of magnetite, Phys. Earth Planet. Inter., 46(13), 24-45, 1987.

Heller, R., R. T. Merrill, and P. L. McFadden, The variation of intensity of earth's magnetic field with time, Phys. Earth Planet. Inter, 131(3-4), 237-249, 2002.

Huang, B., J. D. A. Piper, C. Zhang, Z. Li, and R. Zhu, Paleomagnetism of Cretaceous rocks in the Jiaodong Peninsula, eastern China: Insight into block rotations and neotectonic deformation in eastern Asia, J. Geophys. Res. (Solid Earth), 112(B3), B03106, 2007

Jackson, M., H.-U. Worm, and S. K. Banergee, Fourier analysis of digital hysteresis data: rock magnetic applications, Phys. Earth Planet. Inter., 65(1-2), 78-87, 1990.

Juárez, M. T., L. Tauxe, J. S. Gee, and T. Pick, The intensity of the Earth's magnetic field over the past 160 million years, Nature, 394, 878-881, 1998.

Kee, W.-S., S.-B. Lim, H. Kim, B. C. Kim, S. K. Hwang, K. Y. Song, and Y.-H. Kihm, Geological report of the Yeoncheon sheet, scale 1:50,000, Korea Inst. Geosci. Mineral Resources, 83 pp., 2008.

Kent, D. V., B. M. Honnorez, N. D. Opdyke, and P. J. Fox, Magnetic properties of dredged oceanic gabbros and the source of marine magnetic anomalies, Geophys. J. R. Astron. Soc., 55(3), 513-537, 1978.

Kim, W., S.-J. Doh, Y. Yu, J. J. Lee, and D. Suk, Hydrothermal fluidcontrolled remagnetization of sedimentary rocks in Korea: Tectonic importance of pervasive Tertiary remagnetization, Tectonophysics, 474(34), 684-695, 2009

Kirschvink, J. L., The least-squares line and plane and the analysis of palaeomagnetic data, Geophys. J. R. Astron. Soc., 62(3), 699-718, 1980.

Lee, D. S., K. J. Ryu, and G. H. Kim, Geotectonic interpretation of Choogaryong Rift Valley, Korea, J. Geol. Soc. Korea, 19(1), 19-38, 1983 (in Korean and Chinese with English abstract).

Lee, J.-S., Petrologie et relations structurales des volcanites Cretacees a Cenozoiques de la Coree du Sud: Implications geodynamiques sur la marge est-Eurasiatique, Ph.D. thesis, University of d'Orleans, 1989.

Lee, Y. S., K. D. Min, and J. H. Hwang, The geodynamic evolution of the Chugaryeong Fault Valley in a view point of paleomagnetism, Econ. En- virion. Geol., 34(6), 555-571, 2001 (in Korean with English abstract). Leonhardt, R., F. Hufenbecher, F. Heider, and H. C. Soffel, High absolute paleointensity during a mid Miocene excursion of the Earth's magnetic field, Earth Planet. Sci. Lett., 184(1), 141-154, 2000.

Lowrie, W., Identification of ferromagnetic minerals in a rock by coercivity and unblocking temperature properties, Geophys. Res. Lett., 17(2), 159162, 1990.

McClelland, E. and J. C. Briden, An improved methodology for Thelliertype paleointensity determination in igneous rocks and its usefulness for verifying primary thermoremanence, J. Geophys. Res. (Solid Earth), 101(B10), 21995-22013, 1996.

McFadden, P. L. and R. T. Merrill, Lower mantle convection and geomagnetism, J. Geophys. Res. (Solid Earth), 89(B5), 3354-3362, 1984.

McFadden, P. L. and R. T. Merrill, Asymmetry in the reversal rate before and after the Cretaceous Normal Polarity Superchron, Earth Planet. Sci. Lett., 149(1-4), 43-47, 1997.

Nagata, T., Y. Arai, and K. Momose, Secular variation of the geomagnetic total force during the last 5000 years, J. Geophys. Res. (Solid Earth), 68, 5277-5281, 1963

Olson, P. and V. L. Hagee, Geomagnetic polarity reversals, transition field structure, and convection in the outer core, J. Geophys. Res. (Solid Earth), 95(B4), 4609-4620, 1990.

Olson, P. L., R. S. Coe, P. E. Driscoll, G. A. Glatzmaier, and P. H. Roberts, Geodynamo reversal frequency and heterogeneous core-mantle boundary heat flow, Phys. Earth Planet. Inter, 180(1-2), 66-79, 2010.

Park, Y.-H., S.-J. Doh, I.-C. Ryu, and D. Suk, A synthesis of Cretaceous palaeomagnetic data from South Korea: tectonic implications in East Asia, Geophys. J. Int., 162(3), 709-724, 2005.

Paterson, G. A., A simple test for the presence of multidomain behavior during paleointensity experiments, J. Geophys. Res. (Solid Earth), 116, B10104, doi:10.1029/2011JB008369, 2011.

Perrin, M., J. Riisager, and M. Joseph, Preliminary paleointensity results from dolerite dyke swarm in central Kerala, India, Memoirs Geol. Soc. India, 44, 261-270, 1999.

Pick, T. and L. Tauxe, Geomagnetic palaeointensities during the Cretaceous normal superchron measured using submarine basaltic glass, $\mathrm{Na}$ ture, 366, 238-242, 1993.

Riisager, J., M. Perrin, P. Riisager, and D. Vandamme, Palæomagnetic results and palæointensity of Late Cretaceous Madagascan basalt, $J$. African Earth Sci., 32(3), 503-518, 2001.

Riisager, P. and J. Riisager, Detecting multidomain magnetic grains in Thellier palaeointensity experiments, Phys. Earth Planet. Inter., 125(14), 111-117, 2001.

Selkin, P. A. and L. Tauxe, Long-term variations in palaeointensity, Philos. Trans. R. Soc. Lond. A, 358(1768), 1065-1088, 2000.

Selkin, P. A., J. S. Gee, L. Tauxe, W. P. Meurer, and A. J. Newell, The effect of remanence anisotropy on paleointensity estimates: a case study from the Archean Stillwater Complex, Earth Planet. Sci. Lett., 183(34), 403-416, 2000.

Shcherbakova, V. V., B. Z. Asanidze, V. P. Shcherbakov, and G. V. Zhidkov, Geomagnetic field paleointensity in the Cretaceous from Upper Cretaceous rocks of Georgia, Izv. Phys. Solid Earth, 43(11), 951-959, 2007.

Shcherbakova, V. V., G. V. Zhidkov, and V. P. Shcherbakov, Revised determination of the paleointensity in the Cretaceous from the collection of A. S. Bol'shakov and G. M. Solodovnikov, Izv. Phys. Solid Earth, 44(10), 816-821, 2008

Shcherbakova, V. V., M. Perrin, V. P. Shcherbakov, V. E. Pavlov, A. Ayvaz'yan, and G. V. Zhidkov, Rock magnetic and paleointensity results from Mesozoic baked contacts of Armenia, Earth Planets Space, 61(1), 23-39, 2009.

Shcherbakova, V. V., V. G. Bakhmutov, V. P. Shcherbakov, G. V. Zhidkov, and V. V. Shpyra, Palaeointensity and palaeomagnetic study of Cretaceous and Palaeocene rocks from Western Antarctica, Geophys. J. Int., 189(1), 204-228, 2012.

Sherwood, G. J., J. Shaw, G. Baer, and S. B. Mallik, The strength of the geomagnetic field during the Cretaceous Quiet Zone: Paleointensity results from Israeli and Indian lavas, J. Geomag. Geoelectr., 45, 339360, 1993.

Smirnov, A. V. and J. A. Tarduno, Magnetic hysteresis monitoring of Cretaceous submarine basaltic glass during Thellier paleointensity experiments: evidence for alteration and attendant low field bias, Earth Planet Sci. Lett., 206(3-4), 571-585, 2003.

Smith, P. J., The intensity of the ancient geomagnetic field: a review and analysis, Geophys. J. R. Astron. Soc., 12(4), 321-362, 1967.

Tanaka, H. and M. Kono, Paleointensities from a Cretaceous basalt platform in Inner Mongolia, northeastern China, Phys. Earth Planet. Inter. 
133(1-4), 147-157, 2002.

Tarduno, J. A., R. D. Cottrell, and A. V. Smirnov, The Cretaceous superchron geodynamo: Observations near the tangent cylinder, Proc. Natl. Acad. Sci. USA, 99(22), 14020-14025, 2002.

Tauxe, L., Long-term trends in paleointensity: The contribution of DSDP/ODP submarine basaltic glass collections, Phys. Earth Planet. Inter., 156(3-4), 223-241, 2006.

Tauxe, L., Essentials of Paleomagnetism, 512 pp., University of California Press, Berkeley, 2010.

Tauxe, L. and H. Staudigel, Strength of the geomagnetic field in the Cretaceous Normal Superchron: New data from submarine basaltic glass of the Troodos Ophiolite, Geochem. Geophys. Geosyst., 5(2), Q02H06, doi:10.1029/2003GC000635, 2004.

Thellier, É. and O. Thellier, Sur l'intensité du champ magnétique terrestre dans le passé historique et géologique, Ann. Géophys., 15, 285-376, 1959.

Thomas, D. N., A. J. Biggin, and P. W. Schmidt, A palaeomagnetic study of Jurassic intrusives from southern New South Wales: further evidence for a pre-Cenozoic dipole low, Geophys. J. Int., 140(3), 621-635, 2000. Walker, J. D., J. W. Geissman, S. A. Bowring, L. E. Babcock, and compilers, Geologic Time Scale v. 4.0, Geol. Soc. Am., doi:10.1130/2012.CTS004R3C, 2012.
Walton, D. and W. Williams, Cooling-rate effects in the magnetization of single-domain grains, J. Geomag. Geoelectr., 40, 729-737, 1988.

Yu, Y., High-fidelity paleointensity determination from historic volcanoes in Japan, J. Geophys. Res. (Solid Earth), 117, B08101, doi:10.1029/2012JB009368, 2012.

Yu, Y. and L. Tauxe, Testing the IZZI protocol of geomagnetic field intensity determination, Geochem. Geophys. Geosyst., 6(5), Q05H17, doi:10.1029/2004GC000840, 2005.

Yu, Y., L. Tauxe, and A. Genevey, Toward an optimal geomagnetic field intensity determination technique, Geochem. Geophys. Geosyst., 5(2), Q02H07, doi:10.1029/2003GC000630, 2004.

Zhao, X., R. S. Coe, K.-H. Chang, S.-O. Park, S. K. Omarzai, R. Zhu, Y. Zhou, S. Gilder, and Z. Zheng, Clockwise rotations recorded in Early Cretaceous rocks of South Korea: implications for tectonic affinity between the Korean Peninsula and North China, Geophys. J. Int., 139(2), 447-463, 1999.

Zhao, X., P. Riisager, J. Riisager, U. Draeger, R. S. Coe, and Z. Zheng, New palaeointensity results from Cretaceous basalt of Inner Mongolia, China, Phys. Earth Planet. Inter., 141(2), 131-140, 2004.

B. Chang, W. Kim, S.-J. Doh (e-mail: sjdoh@korea.ac.kr), and Y. Yu 